\title{
PENGEMBANGAN MODUL PRAKTIKUM EFEK FOTOLISTRIK BERBASIS VIRTUAL LABORATORY DENGAN MODEL DISCOVERY LEARNING
}

\author{
Helena Mogi, Theresje Mandang, Jimmy Lolowang \\ Fakultas Matematika dan Ilmu Pengetahuan Alam, Universitas Negeri Manado \\ email: helenamogi2@gmail.com
}

\begin{abstract}
ABSTRAK
Penelitian ini dilatar belakangi oleh belum adanya modul praktikum berbasis virtual laboratory untuk dijadikan pegangan wajib bagi mahasiwa. Sehingga mahasiwa merasa kesulitan dalam memahami konsep fisika yang berkaitan dengan praktikum efek fotolistrik terlebih khusus dalam masa pandemi ini. Penalitian ini bertujuan untuk mengembangkan Modul Praktikum Efek Fotolistrik Berbasis Virtual Laboratory Menggunakan Model Pembelajaran Discovery Learning. Penelitian ini merupakan penelitian pengembangan (research and development) dengan menggunakan model penelitian 4D yang diadaptasi dari model Thiagarajan yaitu define, design, develop, dan disseminate. Hasil penelitian untuk mahasiswa mendapatkan nilai rata-rata $82,75 \%$, sehingga modul masuk dalam kategori layak/valid. Dan pada tanggapan 57,35\% mahasiswa memilih sangat bermanfaat (SB), 42,65\% mahasiswa memilih bermanfaat (B), dan tidak ada mahasiswa yang memilih kurang bermanfaat (KB), dan tidak bermanfaat (TB). Berdasarkan hasil penelitian dapat disimpulkan bahwa telah dihasilkan produk berupa modul praktikum efek fotolistrik berbasis virtual laboratory menggunakan model pembelajaran discovery learning dengan kualifikasi baik dan layak.
\end{abstract}

Kata kunci : Modul Praktikum, Efek Fotolistrik Berbasis Virtual Laboratory, Discovery Learning

\begin{abstract}
This research is motivated by the absence of a virtual laboratory-based practicum module to be used as a mandatory guide for students. So that students find it difficult to understand the concepts of physics related to the photoelectric effect practicum, especially in this pandemic era. This research aims to develop a Virtual Laboratory-Based Photoelectric Effect Practicum Module Using a Discovery Learning Model. This study is a research and development study using the $4 D$ research model adapted from the Thiagarajan model, namely define, design, develop, and disseminate. The results of the study for students got an average value of $82.75 \%$, so that the module was included in the feasible / valid category. And in response $57.35 \%$ of students chose very useful (SB), $42.65 \%$ of students chose useful (B), and no student chose less useful (KB) and not useful (TB). Based on the research results, it can be concluded that the product has been produced in the form of a photoelectric effect practicum module based on a virtual laboratory using a discovery learning model with good and proper qualifications.
\end{abstract}

Keywords : Practicum Module, Photoelectric Effects Based on Virtual Laboratory, Discovery Learning 


\section{PENDAHULUAN}

Pendidikan merupakan salah satu bidang yang terkena dampak positif dari perkembangan teknologi pada abad ke-21, oleh karena itu TIK (Teknologi Informasi Komunikasi) menjadi elemen utama yang digunakan dalam pendidikan. Kegiatan belajar mengajar merupakan suatu kegiatan yang paling pokok, hal ini berarti keberhasilan atau tidaknya sistem pendidikan sangat tergantung pada proses pembelajaran. Pembelajaran merupakan proses kerja sama dan komunikasi antara peserta didik dengan pengajar atau dengan lingkungannya untuk mencapai suatu tujuan tertentu, salah satu pembelajaran yang terdapat di kampus adalah pelajaran yang mempelajari tentang peristiwa alam yaitu fisika (Wardhani, 2012).

Fisika merupakan salah satu cabang IPA (sains) yang mendasari perkembangan teknologi maju dan konsep hidup harmonis dengan alam. Fisika bertujuan agar siswa memiliki kemampuan antara lain: mengembangkan pengalaman untuk dapat merumuskan masalah, mengajukan dan menguji hipotesis melalui percobaan, merancang instrumen percobaan, mengumpulkan, mengolah dan menafsirkan data serta mengkomunikasikan hasil percobaan secara lisan dan tertulis (BSNP, 2007).

Proses pembelajaran Fisika bukan hanya memahami konsep-konsep Fisika, tetapi juga mahasiswa belajar berpikir konstruktif melalui Fisika sebagai keterampilan proses sains, sehingga pemahaman mahasiswa terhadap hakikat Fisika menjadi utuh, baik sebagai proses maupun sebagai produk (Lesmono, Supeno, Riani, 2012). Salah satu permasalahan penting dalam pembelajaran fisika adalah rendahnya kualitas pembelajaran peserta didik. Kualitas proses dan hasil belajar fisika ditentukan oleh banyak faktor,salah satunya ketersediaan sarana laboratorium untuk pelaksanaan eksperimen. Kegiatan eksperimen merupakan hal yang paling penting dalam pembelajaran fisika, kerena aspek produk, proses dan sikap peserta didik dapat di kembangkan. Samsudin,et.al., (2012) menyatakan bahwa melalui kegiatan laboratorium (bereksperimen) dapat melatih sikap ilmiah peserta didik dalam memahami konsep pembelajaran. Salah satu faktor yang mempengaruhi keberhasilan kegiatan laboratorium adalah sumber daya yang mencakup bahan dan peralatan,ruang dan perabot, serta teknisi. selain itu juga di masa pandemi ini, semua kegiatan pembelajaran dilakukan secara daring. sehingga kegiatan praktikum juga dilakukan secara daring.

Berkaitan dengan permasalahan tersebut, perlu di lakukan pembenahan, penyesuaian, dan pembaharuan dalam kegiatan pembelajaran pada masa pandemi covid-19, yakni dengan mengembangkan dan memenfaatkan laboratorium virtual berbasis phet untuk membantu mahasiwa agar proses praktikum atau kegiatan bereksperimen di laboratorium akan tetap terlaksana dengan baik di masa pandemi sekarang ini. Laboratorium virtual mensimulasikan lingkungan dan proses laboratorium yang nyata, dan didefinisikan sebagai lingkungan belajar di mana siswa mengubah pengetahuan teoretis mereka menjadi pengetahuan praktis melakukan percobaan (Woodfield, 2005).

Tujuan penelitian ini adalah mengembangkan Modul Praktikum Efek Fotolistrik Berbasis Virtual Laboratory Menggunakan Model Pembelajaran Discovery Learning pada Mahasiswa Prodi Pendidikan FISIKA SI FMIPA Universitas Negeri Manado di semester genap 2020/2021.

Virtual laboratorium merupakan trobosan untuk memaksimalkan fungsi laboratorium untuk mempelajari konsep fisika efek fotolistrik. Hal itu senada dengan pendapat bahwa virtual laboratory dapat meningkatkan pencapaian akademik dan kemampuan proses sains. Oleh karena itu, pembelajaran virtual laboratory berbasis phet diharapkan dapat mengatasi kegitan praktikum efek fotolistrik pada Mata Kuliah Laboratorium Fisika I di masa pandemi ini, dimana semua kegiatan pembelajaran dilakukan secara daring.

Agar kegiatan eksperimen dapat terlaksana dengan baik, salah satunya memerlukan bahan ajar. Dalam mencapai sasaran pembelajaran, bahan ajar hendaknya mendukung kegiatan belajar mengajar. Untuk itu, bahan ajar yang akan dikembangkan sebaiknya dapat memotivasi mahasiswa untuk menggali informasi lebih besar lagi dari lingkungannya (Widodo dan Jasmadi,2008). Menurut Anwar (2010), modul pembelajaran adalah bahan ajar yang disusun secara sistematis dan menarik yang mencakup isi materi, metode dan evaluasi yang dapat digunakan secara mandiri untuk 
mencapai kompetensi yang diharapkan. Menurut Goldschmid dalam Wijaya (1988), modul pembelajaran sebagai jenis satuan kegiatan belajar yang terencana, di desain guna membantu mahasiswa menyelesaikan tujuantujuan tertentu.

Salah satu strategi pembelajaran yang dapat diterapkan dengan metode eksperimen adalah pembelajaran discovery learning. Pembelajaran discovery learning mengarah pada proses sains yang menjadikan mahasiswa dapat menemukan sendiri pengetahuan yang baru sehingga pengetahuan yang diperoleh dapat berupa pemahaman bukan sekedar ingatan belaka yang hari ini diingat dan besoknya dilupakan. Mahasiswa juga diharapkan agar lebih aktif dalam kegiatan pembelajaran,mahasiwa dibentuk dalam kelompok-kelompok belajar sehinga terjadi proses pertukaran informasi. Mahasiswa juga dituntut untuk berpikir kritis dalam pemecahan masalah, memiliki rasa percaya diri, mandiri, dan mampu bekerja sama dalam tim sehingga dapat memecahkan masalah bersama.

Permasalahan yang ditemukan pada mahasiswa Program Studi Pendidikan Fisika UNIMA pada masa pandemi ini khususnya pada Mata Kuliah Laboratorium Fisika I adalah belum adanya modul praktikum untuk dijadikan pegangan wajib bagi mahasiwa. Sehingga mahasiwa merasa kesulitan dalam memahami konsep fisika yang berkaitan dengan praktikum efek fotolistrik, oleh karena itu perlu di kembangkan modul praktikum yang terintegrasi dengan laboratorium.

\section{METODE PENELITIAN}

Penelitian ini merupakan penelitian pengembangan, atau dikenal dengan Research and Development $(R \& D)$ dengan menerapkan model pembelajaran discovery learning.

Subjek pada penelitian ini adalah mahasiswa Pendidikan Fisika semester IV yang telah mengikuti mata kuliah Laboratorium Fisika I, yang terdiri dari 20 orang mahasiswa,dimana pada uji kelompok kecil berjumlah 5 orang mahasiswa, dan pada uji kelompok besar berjumlah 15 orang mahasiswa.

Adapun model pengembangan media pembelajaran yang digunakan adalah model 4D (four D model) dikemukakan oleh Thiagarajan (1974) dalam (Trianto, 2010:93).
Instrumen penelitian yang digunakan berupa lembar penilaian reviewer, lembar tanggapan mahasiswa kelompok kecil, lembar tanggapan mahasiswa kelompok besar, dan lembar penilaian observasi. Lembar penilaian reviewer digunakan untuk memperbaiki desain dan isi dari modul praktikum agar sesuai dengan model pembelajaran yang digunakan. Lembar tanggapan mahasiswa baik kelompok kecil maupun kelompok besar digunakan untuk mengetahui manfaat panduan praktikum.

Penelitian ini terdiri dari 4 tahap pengembangan, yaitu Define, Design, Develop dan Disseminate. Tahap Define (Pendefinisian) bertujuan untuk menetapkan dan mendefinisikan syarat-syarat pembelajaran. Tahap design ditujukan untuk menghasilkan rancangan mengenai perangkat pembelajaran menggunakan model pembelajaran discovery learning yaitu membuat Modul praktikum efek fotolistrik yang akan membantu mahasiswa dalam kegiatan praktikum di laboratorium. Pada tahap pengembangan, dilakukan langkahlangkah meliputi membuat produk awal yang akan diuji validitasnya oleh ahli dan praktisi, selanjutnya dilakukan revisi sesuai dengan hasil validasi. Proses diseminasi merupakan suatu tahap akhir pengembangan. Tahap diseminasi dilakukan untuk mempromosikan produk pengembangan agar bisa diterima pengguna, baik individu, suatu kelompok, atau sistem.

\section{HASIL DAN PEMBAHASAN}

Berdasarkan rancangan pengembangan maka hasil penelitian ini disesuaikan dengan prosedur atau langkah-langkah rancangan pengembangan 4D (Define, Design, Develop, dan Dissminate) yang ditempuh yaitu sebagai berikut:

\section{Tahap Pendefinisian}

Hasil dari tahap pendefinisian adalah penentuan perangkat yang akan dikembangkan. Tahap ini meliputi 5 langkah pokok, yaitu: a. Analisis Ujung Depan (Front-End analysis)

Hasil Analisis ujung depan yaitu memunculkan dan menetapkan masalah dasar yang dihadapi dalam pembelajran fisika di Jurusan Fisika Unima antara lain belum adanya modul praktikum virtual menggunakan aplikasi PEhT khususnya untuk alat efek fotolistrik dan kurangnya keahlian dalam penggunaan alat laboratorium tersebut maka diperlukan bantuan berupa modul praktikum.

b. Analisis Mahasiswa (Learner Analysis) 
Dari hasil analais ini, mahasiswa merasa akan mendapat kesulitan jika tidak ada modul praktikum disamping itu mahasiswa membutuhkan referensi teori yang memadai.

c. Analisis Tugas (Task Analysis)

Hasil dari analisis tugas yaitu tugas yang dikerjakan belum memenuhi standar referensi teori dan prosedur pelaksanaan praktikum belum memadai.

\section{d. Analisis Konsep (Concept Analysis)}

Hasil dari analisis konsep ini yaitu modul praktikum harus memiliki referensi yang lengkap untuk membantu proses pembelajaran di laboratorium.

e. Perumusan Tujuan Praktikum (Specifying Instructional Objectives)

Pada langkah ini dilakukan perumusan tujuan praktikum dan indikator ketercapaian kompetensi pada modul praktikum efek fotolistrik setelah melakukan pembelajaran.

\section{Tahap Perancangan}

Perancangan ini dimulai dengan memperhatikan modul praktikum laboratorium fisika yang sebelumnya sudah ada kemudian dikembangkan meliputi materi,spesifikasi peralatan yang tidak tertera (nama dan fungsi bagian-bagian alat) dan disesuaikan dengan model pembelajaran berbasis discovery learning. Pada tahap ini dilakukan penilaian reviewer oleh tim ahli/pakar di bidang paraktikum fisika. penilaian dilakukan oleh 2 pakar, yang menilai desain dan isi modul praktikum dari peneliti. Tim ahli / pakar menilai 2 bagian yaitu desain secara umum dan kelengkapan rancangan modul praktikum berdasarkan tujuan yang ingin dicapai.

Untuk bagian desain seacara umum aspek yang diamati antara lain derajat keinovatifan, tingkat kreatifitas, orginalitas, keberfungsian, dan kemanfaatannya bagi Jurusan. Untuk bagian kelengkapan modul praktikum antara lain orientasi, merumuskan masalah, merumuskan hipotesis, menentukan variabel, merangkai percobaan, mengumpulkan data, menguji hipotesis, dan merumuskan hipotesis dan merumuskan kesimpulan.

Tim ahli / pakar pertama melakukan penilaian sebanyak satu kali baik desain secara umum maupun kelengkapan modul praktikum dapat direkomendasikan untuk pelaksanaan modul praktikum tapi harus ditingkatkan pada bagian kelengkapan rancangan modul berdasarkan tujuan yang ingin dicapai yaitu di bagian data dan anlisis data, kemudian dianalisis berdasarkan skor penilaian mencapai 91,66\% dan modul praktikum yang dinilai oleh pakar masuk dalam kriteria baik.

Tim ahli / pakar kedua melakukan penilaian sebanyak dua kali. Pada penilaian pertama, pakar memberikan masukan untuk perbaikan panduan, yaitu penomoran rumus pada materi, dan langkah-langkah percobaan yang akan digunakan. Pada penilaian kedua , pakar hanya memberikan masukan yaitu perlu meningkatkan originalitas dan memiliki catatan layak untuk digunakan pada praktikum efek fotolistrik dan direkomendasikan untuk dapat didesiminasikan lebih luas.

\section{Tahap Pengembangan}

Pada tahap ini modul praktikum akan digunakan dalam menguji keberfungsian alat simulasi PhET praktikum efek fotolistrik, dimana modul praktikum telah dibuat berdasarkan materi yang disesuaikan dengan alat yang mengunakan modul tersebut untuk praktikum efek fotolistrik.

\section{Uji Kelompok Kecil}

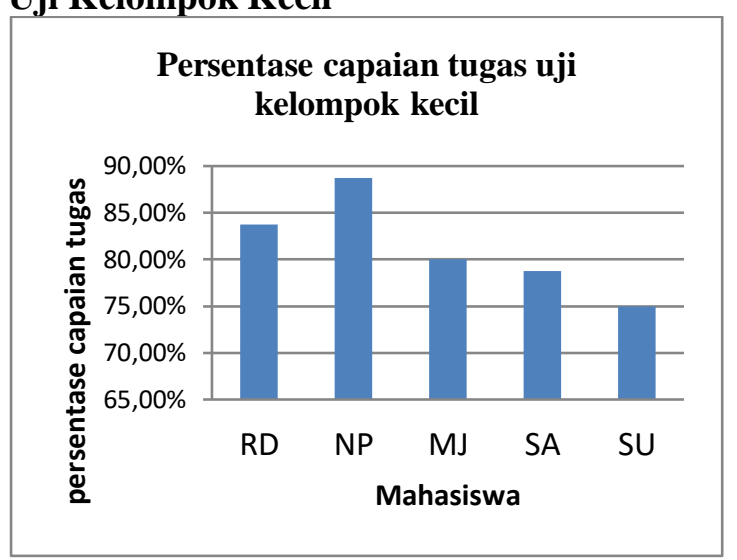

Gambar 1. Presentase capaian tugas kelompok kecil

Dalam kegiatan praktikum, kelompok kecil terdiri dari 5 orang mahasiswa.Pada uji coba kelompok kecil nilai capaian yang dicapai adalah $83,75 \%, 88,75 \%, 80,00 \%, 78,75 \%$, dan $75,00 \%$ sehingga presentasi capaian tugas, dilihat dari 5 orang mahasiswa memperoleh nilai rata-rata $81,25 \%$, sehingga modul praktikum masuk dalam kategori layak. Berikut tanggapan mahasiswa kelompok kecil terhadap modul praktikum efek fotolistrik.

Data yang diperoleh dari 5 orang mahasiswa yang mengikuti praktikum efek fotolistrik menggunakan aplikasi PheT Colorado. Hasil perhitungan total frekuensi dan 
persentase terlihat bahwa $48 \%$ respon kelompok mahasiswa memilih pilihan kategori "Sangat bermanfaat (SB)", 52\% respon kelompok mahasiswa memberi pilihan kategori "Bermanfaat (B)" yang berarti penilaian positif dari kelompok mahasiswa terhadap indikatorindikator yang ditanyakan $100 \%$. Dan tidak ada mahasiswa yang yang memberi pilihan untuk kategori "Kurang Bermanfaat (KB)" dan kategori "Tidak Bermanfaat (TB)". Hasil dari tanggapan mahasiswa kelompok kecil yang memberikan tanggapan $100 \%$ positif, menandakan modul praktikum yang dibuat dan diujicobakan secara lab virtual membuat mahasiswa tertarik menggunakan aplikasi tersebut karena bermanfaat dalam kegiatan praktikum. Dimana dalam proses ini dapat meningkatkan minat mahasiswa dalam melaksanakan kegiatan praktikum fisika serta mahasiswa dapat menemukan konsep-konsep fisika dalam kegiatan praktikum. Setelah modul praktikum di uji cobakan ke kelas lain yaitu pada tahap diseminasi.

\section{Tahap Pendiseminasian}

Proses diseminasi merupakan suatu tahap akhir pengembangan. Tahap diseminasi dilakukan untuk mempromosikan produk pengembangan agar bisa diterima pengguna, baik individu, suatu kelompok, atau sistem. Diseminasi bisa dilakukan di kelas lain dengan tujuan untuk mengetahui efektifitas penggunaan alat penunjang praktikum dalam proses praktikum efek fotolistrik. Bentuk diseminasi ini dengan tujuan untuk mendapatkan masukan, koreksi, saran, penilaian, untuk menyempurnakan produk akhir pengembangan agar siap diadopsi oleh para pengguna produk modul paraktikum ini.

\section{Uji Kelompok Besar}

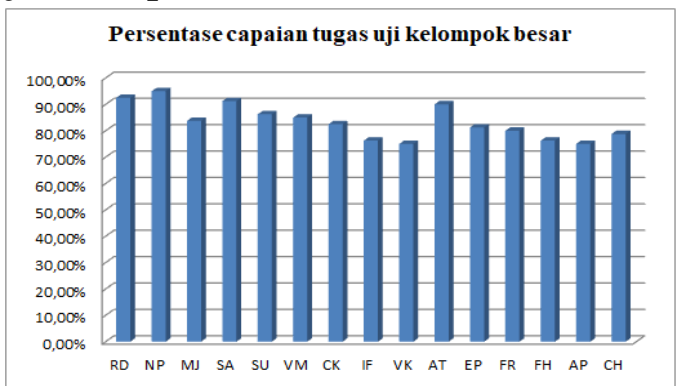

Gambar 2. Presentase capaian tugas kelompok besar

Dalam kegiatan praktikum, kelompok besar terdiri dari 15 orang mahasiswa.Pada uji coba kelompok besar nilai capaian yang dicapai adalah 92,50\%, 95,00\%, 83,75\% , 91,25\%, $86,25 \%, 85,00 \%, 82,50 \%, 76,25 \%, 75,00 \%$, $90,00 \%, 81,25 \%, 80,00 \%, 77,50 \%, 88,75 \%$, dan $78,75 \%$ sehingga presentasi capaian tugas, dilihat dari 15 orang mahasiswa memperoleh nilai rata-rata $84,25 \%$, sehingga modul praktikum masuk dalam kategori layak. Berikut tanggapan mahasiswa kelompok besar terhadap modul praktikum efek fotolistrik.

Data yang diperoleh dari 15 orang mahasiswa yang mengikuti praktikum efek fotolistrik menggunakan aplikasi PheT Colorado. Hasil perhitungan total frekuensi dan persentase terlihat bahwa $66,7 \%$ respon kelompok mahasiswa memilih pilihan kategori "Sangat bermanfaat (SB)", 33,3\% respon kelompok mahasiswa memberi pilihan kategori "Bermanfaat (B)" yang berarti penilaian positif dari kelompok mahasiswa terhadap indikatorindikator yang ditanyakan 100\%. Dan tidak ada mahasiswa yang yang memberi pilihan untuk kategori "Kurang Bermanfaat (KB)" dan kategori "Tidak Bermanfaat (TB)".

\section{KESIMPULAN}

Berdasarkan kajian teori dan pembahasan hasil penelitian dapat disimpulkan sebagai berikut: Modul praktikum efek fotolistrik berbasis virtual laboratory sudah layak digunakan karena sudah melewati tahap-tahap prosedur penelitian pengembangan dan model pembelajaran berbasis Discovery Learning.

\section{REFERENSI}

Alatas, F., Pohan, H., \& Nisa, A. S. (2017). The Implemention of Virtual Laboratory PhET Guided Discovery Learning on Students' Achievement: Advances in Social Science, Education Dynamic Electricity Topic. and Humanities Research, volume 115.

Huda, C., \& Sulisworo, D. (2016). Pengembangan Modul Fisika Dasar Berbasis Virtual Laboratory Di Universitas PGRI Semarang . Prosiding Seminar Nasional Quantum .

Jibrael.Yohan. (2020). Pengembangan Panduan Praktikum Generator Satu Fase Dan Tiga Fase Berbasis Inkuiri Terbimbing Dengan Mentoring. Skripsi. Tondano: Universitas Negeri Manado.

Matialo, B. R. (2017). Pengembangan Panduan Praktikum Fisika Untuk Alat Geometrical Optics Laser Menggunakan Model 
Pembelajaran Discovery Learning. Skripsi. Tondano: Universitas Negeri Manado.

Mosu'a, K. F. (2017). Pengembangan Perangkat Pembelajaran Fisika Berbasis Eksperimen Virtual Dengan Model Inkuiri Terbimbing Materi Hukum Newton Dan Penerapannya. Skripsi. Tondano. Universitas Negeri Manado.

Nafaida, R., Halim, A., \& Rizal, S. (2015). Pengembangan Modul Berbasis Phet Untuk Meningkatkan Pemahaman Konsep Dan Motivasi Belajar Siswa Pada Materi Pembiasan Cahaya. Jurnal Pendidikan Sains Indonesia, Vol.03, Hlm 181-185.

RANJAN, A. (2017). EFFECT OF VIRTUAL LABORATORY ON DEVELOPMENT OF CONCEPTS AND SKILLS IN PHYSICS. International Journal of Technical Research \& Science, 2 (1), 2454- 2024.

Sugiono. (2010). Metode Penelitian Kuantitatif Kualitatif Dan R\&D.

Sutrisno. (2006). Fisika Dan Pembelajaranya. Bandung: UPI.

Yusuf, I., \& Subaer. (2013). Pengembangan Perangkat Pembelajaran Fisika Berbasis Media Laboratorium Virtual Pada Materi Dualisme Gelombang Partikel Di Sma Tut Wuri Handayani Makassar. Jurnal Pendidikan Ipa Indonesia , Vol.2, 189194.

Yusuf, I., Widyaningsih, S. W., \& Purwati, D. (2015). Pengembangan Perangkat Pembelajaran Fisika Modern Berbasis Media Laboratorium Virtual Berdasarkan Paradigma Pembelajaran Abad 21 Dan Kurikulum 2013. OPancaran, Vol.4, Hal 189-200. 